\title{
Pedagogía crítica, bases para una escuela democrática
}

\section{Sandra Vega Villarreal*}

Resumen. Bajo la recomendación de los organismos financieros, en México se ha implementado una política orientada a disminuir sustancialmente la inversión del gasto social del Estado y con ello abrir espacios a la inversión privada en la prestación de servicios. El sector educativo ha sido sometido a diversas reformas en consideración al supuesto empresarial de alcanzar la calidad junto a la implementación de mecanismos que restringen el acceso de la población estudiantil a la educación. La evaluación estandarizada justifica un modelo pedagógico centrado en contenidos y orientado al entrenamiento de los estudiantes para que sean capaces de responder a los exámenes. Develar las relaciones políticas que se establecen en los procesos educativos es un cometido de la pedagogía crítica. Una premisa fundamental es romper con la educación bancaria, cuya denominación se deriva del acto de educar traducido a un depósito de comunicados por quien conoce sobre el que ignora. La palabra adquiere un valor como medio para acceder al proceso de concienciación y empoderamiento para actuar sobre la realidad. La pedagogía crítica no se limita a la denuncia, sino que, a través de la noción de comunicación, brinda elementos para construir un modelo pedagógico liberador. Así, se conceptualiza un sujeto capaz de enfrentar la dominación. Para emanciparse de una realidad opresiva se requiere un proceso educativo profundo, amplio y permanente, donde los oprimidos participen activamente en la reflexión y la acción liberadora.

Palabras clave: pedagogía crítica, escuela democrática, educación, dominación, emancipación.

* Docente investigadora de la Universidad Pedagógica Nacional del Estado de Chihuahua (UPNECH) y del Instituto de Pedagogía Crítica (Ipec), México. 


\section{Critical pedagogy, the foundation for democratic schools}

Abstract. Following the recommendations of financial institutions, Mexico has put in place a policy which aims to substantially reduce investment in social spending by the State and in doing so, opens the way for private investment in the delivery of services. The education sector has been subjected to various business-oriented reforms intended to attain «quality» in tandem with the imposition of mechanisms that restrict access to education for the student population. In addition, standardized evaluation is used to justify a pedagogical model focused on content and oriented toward the training of students to pass examinations. Thus, critical pedagogy reveals the political relationships that are embedded in educational processes. At its core is a disconnect from the 'banking education» concept, where the act of educating is viewed as a process of «depositing» knowledge from those who know to those who do not. The word takes on a value as a way of accessing the process of building consciousness and empowering in order to act in changing reality. However, critical pedagogy is not limited to raising complaint, but rather, within the language of possibility, it offers the tools to build a model of liberation pedagogy via communication. In order to be freed from an oppressive reality, a deep, broad and continuous process of education is required, where the oppressed participate actively in the debate and liberating action.

Keywords: critical pedagogy, democratic school, education, domination, emancipation. 


\section{Introducción}

Como educadores que nos educamos con grupos en situación de vulnerabilidad económica, social, cultural y de género, asistimos a procesos sociales de desigualdad, pobreza y marginación generados por el sistema económico neoliberal que se ha empeñado en hacerse cuerpo con nosotros, en cada espacio de nuestras vidas, a través de elementos concretos que están presentes en nuestra cotidianeidad. La lógica neoliberal ha utilizado una diversidad de medios y dispositivos para mantenerse y acrecentar su poder. En México se han implementado políticas públicas que sugieren organismos financieros como el Banco Mundial (BM) y el Fondo Monetario Internacional (FMI), cuyo interés es disminuir la inversión del gasto social del Estado y abrir camino a la inversión privada en la prestación de servicios.

En el ámbito educativo se han realizado una serie de reformas durante los últimos años bajo el supuesto empresarial de alcanzar una calidad en la educación, para ello proponen mecanismos de operación que agravan el escaso acceso de la población al sistema educativo. Estas reformas sientan como eje vertebrador la evaluación de los profesores, a quienes se les responsabiliza de manera directa y descontextualizada de los resultados obtenidos en evaluaciones aplicadas por organismos como Programa Internacional para la Evaluación de Estudiantes (PISA, por sus siglas en inglés), que se aplica a países pertenecientes a la Organización para la Cooperación y el Desarrollo Económicos (OCDE), donde México participa en condiciones de seria desventaja económica.

La exigencia de responder a estándares justifica un modelo pedagógico centrado en contenidos (Kaplún, 2002), el cual deberá tener como 
centro de atención el entrenamiento de estudiantes para que emitan respuestas a exámenes. Esto implica que se cuestionen las formas en que se promueve el aprendizaje en las aulas, la participación del profesor en la transmisión de contenidos y, por supuesto, el papel del alumno. El cuestionamiento generado a partir de los supuestos psicológicos conductistas que subyacen y la pedagogía transmisora que le enviste, nos lleva más allá de las fronteras de los procesos áulicos y nos introduce al ámbito político. Develar las relaciones políticas que se establecen en los procesos educativos es un cometido de la pedagogía crítica. De ahí la necesidad de realizar un cuestionamiento profundo al modelo establecido en México de forma reciente, no sólo por sus implicaciones pedagógicas y psicológicas, sino por el impacto social que ha tenido en los sectores económicamente desfavorecidos y en grupos vulnerables, quienes representan la población a favor de la cual toma partido la pedagogía crítica.

Ante este panorama, quienes hemos estado construyendo un posicionamiento teórico desde la perspectiva de la pedagogía crítica, somos interpelados por la realidad. Sentimos la necesidad de resignificar los supuestos de esta corriente teórica para leer el contexto, develar contradicciones y construir estrategias a fin de actuar en su transformación. Al respecto, como una necesidad apremiante, el equipo del Instituto de Pedagogía Crítica (Ipec) nos hemos propuesto la tarea de recuperar sus premisas fundamentales, para que en diálogo con el contexto y nuestra experiencia en la formación docente, en la investigación y el trabajo con grupos socialmente vulnerables, podamos brindar elementos para la construcción de un modelo pedagógico democrático que apoye a los actores educativos desde las escuelas y comunidades. El presente escrito manifiesta un esfuerzo inicial en esta ardua tarea. Por tal motivo comienza por hacer explícitas las nociones de 
la pedagogía crítica que contribuyan a realizar un análisis crítico de la realidad. Se recurrirá principalmente a las aportaciones de Paulo Freire (1997) y algunos pedagogos latinoamericanos que han desarrollado esta perspectiva en ámbitos específicos de la comunicación, la educación y la cultura. También se rescatan aportaciones de pedagogos estadounidenses que han sistematizado elementos importantes para caracterizar a la pedagogía crítica desde su interacción.

Sin embargo, no se puede dejar de lado los aportes de la Escuela de Frankfurt y otros teóricos de la sociología crítica que con sus aportaciones han enriquecido la pedagogía crítica, sobre todo lo relacionado con los procesos de dominación, hegemonía, resistencia y emancipación, que se desarrolla en la segunda parte. Finalmente, se esbozan elementos que pudieran contenerse en un modelo pedagógico sustentado en la pedagogía crítica. Se destacan los principios pedagógicos, psicológicos y, en particular, políticos a considerarse en la relación que se establece en diversos ámbitos, que sin la intención de ser una receta, brinden pautas a educadores e investigadores; se pretende construir en colectivo una propuesta que permita incidir en nuestro contexto inmediato a través del trabajo pedagógico.

\section{Presupuestos generales de una pedagogía crítica}

Una premisa esencial de la pedagogía crítica es romper con la educación bancaria, cuya denominación se deriva del acto de educar traducido a un depósito de comunicados por quien conoce sobre el que ignora. Este acto se desarrolla, principalmente, mediante la disertación y se emplea el 
verbalismo como método básico para transmitir la información. Este acto transmisivo ubica al educador como una figura central, pues será él quien tiene la legitimidad de elegir los contenidos que serán depositados. Su autoridad es indiscutible, dado que le enviste el poder legítimo de llenar los recipientes a su cargo. Este poder se lo otorga el saber reconocido a través de su formación profesional, que lo faculta para prescribir lo que los educandos deben aprender, para dictar las reglas de disciplina que deberán seguir, pues se le reconoce la capacidad de pensar las opciones educativas que se consideran correctas para los educandos.

Una pedagogía bancaria lleva en su esencia el ejercicio de poder unilateral por el educador sobre los educandos, quienes son reducidos a cosas sobre las cuales se deposita de manera mecánica la verdad sobre una realidad estática, inmutable, abstracta y ajena a su vida. Este proceso de recepción pasiva de los educandos-recipientes frena todo proceso de actividad creativa, reflexiva y encamina hacia la adaptación de una sociedad ya establecida, por lo que un proceso de aprendizaje auténtico queda descartado, ya que «sólo existe saber en la invención, en la reinvención, en la búsqueda inquieta, impaciente, permanente que los hombres realizan en el mundo, con el mundo y con los otros» (Freire, 1990:52). Será el rompimiento con la educación bancaria un epicentro para la construcción de una propuesta pedagógica crítica, que no sólo busque construir relaciones democráticas entre educador y educando, sino que trasciende a cuestionar incisivamente el orden social autoritario con fines de transformarlo.

Otro elemento indispensable de la pedagogía crítica es el valor que se le confiere a la palabra como medio a través del cual se accede al proceso de concienciación y empoderamiento para actuar sobre la realidad. De ahí la necesidad de romper con esquemas del modelo extensionista, dado que 
favorece una relación política de dominación por medio de una comunicación unidireccional, donde alguien que se considera en una posición de poder superior transmite comunicados a otra persona que es concebida como inferior por lo que favorece una relación de dominación, convirtiendo a quien recibe en «casi cosa, lo niegan como ser capaz de transformar el mundo» (Freire, 1990:21), eso implica que se le invada culturalmente; es decir, se trata de un conocimiento determinado, pensado, ideado y reconocido como válido y legítimo por una cultura específica que se extiende hacia otra cultura que de acuerdo a la estratificación social se considera inferior.

El acto donde la palabra de una cultura dominante mutila la palabra de otra cultura, la de los oprimidos, no sólo les niega la posibilidad de conocer las significaciones del mundo, sino la generación de nuevos sentidos de los hablantes desde los que puedan reinventar el presente y construir el futuro (Martín, 2002). Esta invasión cultural se desarrolla mediante diversos procesos, algunos muestran un rostro más duro que otros, pero finalmente el resultado es el mismo: transmitir, traspasar las ideas hegemónicas del mundo que los oprimidos deben recitar y con ello suplantar su voz para impedirle que piense y construya su mundo. Uno de los procesos más comunes a través de los cuales se da la invasión cultural es la manipulación, la cual se da en apariencia en un acto de comunicación mesiánico, es decir, el que posee el saber legitimado, el sabio, acerca generosamente su saber al ignorante, quien deberá recibirlo sin cuestionar, aceptar la verdad del otro como suya. Freire desarrolla esta noción ejemplificando con las labores que realizaban los agrónomos extensionistas en la década de 1970, donde había que persuadir a los campesinos peruanos y de otras regiones de América Latina para que renunciaran a sus creencias, saberes y tradiciones para que acepten el saber científico, válido, generalizable que llevan los extensionistas. 
El nodo de «la dominación habita en el lenguaje a través de dispositivos de neutralización y amordazamiento de la acción — del trabajo — contenida en la palabra. El gusto por la palabra hueca, por la palabrería no es sino la contracara del mutismo profundo que se expresa en la ausencia de participación y decisión» (Martín, 2002:27). Con la supresión del derecho a decir su palabra, los oprimidos son presas fáciles de dominación ideológica que se les presenta como omnímoda, irrefrenable, pues se muestra bajo la forma de pensamiento único, que contiene los saberes válidos para habitar este mundo.

De manera insospechada, cuando los oprimidos se han acostumbrado a que en sus espacios resuene la voz del púlpito como la representante de ellos mismos, han aceptado e incluso legitimado el poder que les cosifica, que les prepara para aceptar el funcionamiento de un sistema social que no les oprime y poner a la disposición de este funcionamiento sus energías y recursos, que se traduce inefablemente en un acto tácito de violencia simbólica (Bourdieu, 2000). Es evidente que el modelo extensionista que legitima la supremacía de un lenguaje y una cultura dominante, responde a la lógica neoliberal, que no sólo ha generado brechas insondables de desigualdad entre pobres y ricos, sino que implanta una cultura que genera el racismo, el sexismo, la homofobia, la exclusión social.

No obstante, la pedagogía crítica no se limita a la denuncia, sino que, acudiendo al lenguaje de la posibilidad, a través de la noción de comunicación brinda elementos para construir un modelo pedagógico liberador. La comunicación es concebida como un proceso dialógico de interacción entre sujetos que comparten un código común, mediados por un objeto de comunicación del cual cada uno hará construcciones originales. Por tanto, se reconoce como un proceso donde no existen jerarquías entre lenguas, 
culturas, conocimientos ni una relación de poder unilateral. Esto permitirá el encuentro entre los hombres para cuestionar el mundo, pues el saber y la cultura son construcciones colectivas, que surgen de un interés intrínseco de los oprimidos y lo representan con sus propias palabras.

Otro elemento imprescindible de la pedagogía crítica es la conceptualización del hombre como sujeto capaz de enfrentar la dominación. Aunque reconoce que la determinación estructural está presente en los actos de los sujetos, pues se exponen a aparatos ideológicos que los llevan a introyectar la ideología dominante que los aliena; también destaca que la dominación nunca es total y apela a la capacidad de los sujetos para resistir a ella. Por ende, la comunicación en tanto acto dialógico se desarrolla entre sujetos en praxis que permite reflexionar sobre sí y su actividad. La relación dialógica se da entre sujetos pensantes, pues «no se puede pensar solo: no se piensa sin la coparticipación de otros sujetos, en el acto de pensar, sobre el objeto, y esta coparticipación de los sujetos en el acto de pensar, sólo se da en la comunicación» (Freire, 1990:75). Aunque no existen sujetos pasivos, su participación en la transformación de la realidad no es cuestión de voluntad, ya que su actuar está históricamente determinado por la formación social donde se gesta. Develar la naturaleza política del proceso educativo es uno de los objetivos de la pedagogía crítica, por tanto se hacen evidentes actos de dominación, así como de resistencia a la opresión. Se funda en la premisa de que todo ejercicio de poder conlleva un contrapoder. Se interesa en los enfrentamientos, luchas multiformes, simbólicas, verbales y no verbales, culturales, étnicas y aquellas que se dan en torno al poder.

El enfrentamiento político no se explica sin la noción de concienciación, que Freire identifica como producto de un proceso educativo liberador que se desarrolla a través de la comunicación, donde se conjugan 
la denuncia y el anuncio, que se realizan críticamente en el proceso de la lectura del mundo, dan origen al sueño por el que luchamos. Este proyecto, que se va perfilando en el proceso de análisis crítico de la realidad que denunciamos, es, para la práctica transformadora de la sociedad, lo que el diseño de la pieza que va a producir el operario, tiene en su cabeza antes de hacerla, para poder realizarla (Freire, 2001:53).

La noción de comunicación aporta pautas fundamentales para generar procesos transformadores en el trabajo educativo en las escuelas, comunidades o grupos sociales. Sin embargo, la representación que aquí se detalla ha sido construida a partir de mi experiencia y posicionamiento teórico, así como de la interacción con pedagogos y pensadores críticos de América Latina y de otras partes del mundo, por lo que las ideas expuestas no dependen de limitaciones geográficas. Partiendo del principio de que sin concienciación no se genera emancipación, enunciaré una serie de momentos que visualizan cómo se gesta y desarrolla este proceso.

Emanciparse de una realidad opresiva implica un proceso educativo profundo, amplio y permanente, donde oprimidos participen de manera activa en reflexión y acción liberadora. Este proceso inicia con la problematización de la realidad destacando el análisis político, económico y cultural de una realidad cotidiana en la que se está inmerso, pues ello permitirá identificar la situación de opresión, comprenderla, dimensionarla y visualizarse frente a ella. Aunque la problematización parte de experiencias concretas de la vida cotidiana, debe ser integrado con un posicionamiento teórico crítico por el educador que está interactuando con el grupo social en cuestión. Con esto no quiero decir, de ninguna manera, que el educador solamente tendrá las herramientas teóricas y las extenderá a los oprimidos, sino que tendrá que 
saber utilizar esas herramientas para complementar el análisis que expresan los oprimidos, rescatando su palabra, guardando silencio para tener una comunicación verdadera con ellos, pero sin renunciar a su palabra, a su cultura y a la formación teórica que posee.

El proceso de problematización se realiza mediante una comunicación dialógica, en la cual hay sujetos que comparten su palabra y su visión del mundo con los otros, donde lo más importante es que los involucrados se asuman como actores principales y comprometan sus acciones en busca del beneficio común, más allá de su individualidad, la cual no desaparecerá sino que pasará a conformar un cuerpo colectivo con el que, conservando rasgos individuales, estará comprometida su reflexión y su acción, ello establece las bases para que pueda trascenderse hacia una denuncia social donde los grupos sociales oprimidos se encuentran y exponen las injusticias y opresiones de las que son objeto, además de compartir compromisos y formas de enfrentar y transformar la realidad. Lo anterior exige que la acción se desarrolle de manera consciente, reflexionada y organizada colectivamente. Entonces se dará paso a la anunciación.

La anunciación puede ser posible una vez que la colectividad ha vivido un proceso de formación crítica sobre su realidad, que ha aprendido a cuestionarla, desentrañar los mecanismos de poder que le oprimen y ha logrado conformarse en un bloque histórico, con intenciones y objetivos claros de luchar por objetivar sus intereses como grupo o clase social (Poulantzas, 1985). Todo esto se verá reflejado en cada momento de la acción, pues en el acto educativo liberador todos participan conjuntando esfuerzos, estrategias, formas y mecanismos concretos para la transformación de la realidad. El proceso de concienciación que podrá derivar en la construcción de una realidad mejor precisa en todo momento del diálogo, entendido éste como 
la forma dialéctica de intercambiar ideas, respetando, escuchando y construyendo a partir de la palabra del otro. Pues la palabra, «a la vez que activa/ despliega el espesor de significaciones sedimentadas en ella por la comunidad de hablantes, se hace posible la generación de nuevos sentidos desde los que reinventar el presente y construir el futuro» (Martín, 2002:20). En ese sentido, hasta que los grupos oprimidos expresen su palabra y la concreticen en la reflexión-acción, estarán en camino a la liberación.

El proceso pedagógico liberador conlleva un proceso educativo para la vida, pues en él, más allá de contenidos o propaganda, mujeres y hombres aprenden a leer el mundo de manera crítica, a penetrar su apariencia, a comprenderlo a partir de las relaciones que establecen con él y a reflexionar su actuar y posibilidades de cambio. De ahí que el proceso liberador no se viva sólo en un momento, sino que es permanente, continuo y cambiante de acuerdo con las condiciones históricas que se estén enfrentando. Quienes se involucran en este modelo pedagógico lo convierten en su forma de vida, pues se convierten en seres colectivos, en praxis, que continuamente leen de manera crítica la realidad, se organizan para actuar sobre ella, juzgan su acción, la replantean, enriquecen o cambian, según sea necesario.

\section{Pedagogía crítica para la concienciación y contra la alienación}

La concienciación es el elemento político central de la pedagogía crítica, y se concretiza en el cuestionamiento a los fines educativos. Hace explícito el posicionamiento político al pronunciarse por una educación liberadora a partir de la denuncia del sentido alienante del proceso pedagógico, encarnado en la educación invasiva, trasmisora, discursiva, donde el papel 
central de este acto es ocupado por el educador y el educando es reducido a un objeto repositorio donde se colocan verdades legitimadas por la autoridad poseedora del saber. Esta relación mecanicista conlleva a un proceso de alienación tanto para quien educa como para quien es educado.

La alienación del profesor se puede equiparar a la alienación del hombre con el producto de su trabajo, el cual, después de creado lo lleva a convertirse en rehén de las circunstancias históricas, como señala Marx: «La conciencia se enfrenta al hombre como un poder absolutamente extraño, omnipotente e inexpugnable, ante el que los hombres se comportan de un modo puramente animal y los amedrenta como ganado» (1974:31). Este acto se consuma cuando el profesor se asume como el sabio que magnánimamente extiende su sapiencia a los marginados, no cobra conciencia que desconoce, por lo que al no saber que no sabe muchas cosas, habrá dejado de aprehender el mundo. Desde su perspectiva, considera que ha acumulado una serie de saberes inmutables, que no hacen sino obnubilar su conciencia y hacerlo preso de conocimientos que cree poseer. De esta manera, aunque se cree sujeto, se convierte en objeto, en un rehén de su autoridad pedagógica a la cual, obedece acríticamente y le entrega su capacidad creadora, de construcción en interacción con los otros.

Podría decirse que la alienación del hombre con su actividad se equipara con la alienación de la que es objeto el estudiante cuando se le impone el desarrollo de actividades ajenas a sus necesidades, a su experiencia y a su vida. En estas actividades, el estudiante pierde tiempo al dedicar sus energías y recursos a algo que no forma parte de sí, sino que la realiza por coerción, lo cual genera un sentimiento de tedio y hostigamiento, pues «no se afirma en su trabajo, sino que se niega en él, no se siente feliz, sino desgraciado, no desarrolla al trabajar sus libres energías físicas y espirituales, 
sino que, por el contrario, mortifica su cuerpo y arruina su espíritu» (Marx, 1982:598). Queda claro que la emancipación con respecto a los mecanismos de dominación no es cuestión de voluntad de los sujetos. En tanto productos y productores de historia, los individuos, obligados por la posición que ocupan en las relaciones de producción, realizan acciones no conscientes que los hacen cómplices de su dominación. De ahí que, para ampliar este análisis, resulte necesario rescatar las nociones de ajustamiento e incorporación para entender, desde un contexto latinoamericano, el desarrollo de un proceso educativo alienante que fortalece a una sociedad autoritaria, excluyente e injusta. Se desarrolla también la noción de integración social que plantea participar en decisiones sociales a favor de los oprimidos.

La noción de incorporación se da cuando el hombre se ve obligado a relacionarse con un mundo que le es ajeno, proviene del exterior y representa intereses que no son los suyos, pero los tendrá que asimilar, deberá ajustar su conducta a las normas que estos procesos sociales le dicten. Un ejemplo muy ilustrativo se da en las sociedades coloniales de América Latina, cuando los colonizadores invaden su tierra, su cuerpo, su lengua y su cultura. En la incorporación, el pueblo vive un proceso de ajuste al principio obligado, después alienado. De tal modo que desarrolla mecanismos que permiten adaptarse a la vida ajena que se impone y lo ubica como un ser marginado en la toma de decisiones, aunque puede participar en asuntos relacionados con la organización social, su participación se limita a cumplir con estándares exigidos. Por ello se encarna en una pedagogía invasiva, alienante, posicionada en una perspectiva funcionalista, en tanto concibe a la sociedad como un todo armónicamente constituido, de tal forma que los sujetos que en ella se desenvuelven, no hacen sino adaptarse a la estructura y reglas establecidas por el sistema social, que se han ido 
construyendo a través de la historia y transmitiendo de generación en generación (Durkheim, 2001).

Para lograr que la colectividad se ajuste a mandatos del sistema social establecido, cuenta con mecanismos concretos para la reproducción y regulación social de los individuos, quienes deberán asumir metas y objetivos colectivos desapareciendo sus aspiraciones y necesidades individuales. La sociedad debe contar con medios para difundir una cultura encaminada a mantener una cohesión social, que permita al sistema operar funcionalmente y mantenerse (Parsons, 1984). En otras palabras, la sociedad y su gran maquinaria deben funcionar buscando que en los individuos que la componen no haya deslices ideológicos ni de ningún tipo que puedan provocar la alteración del orden establecido.

La incorporación a la sociedad actual exige cada vez mayor especialización de sus miembros, cada individuo deberá prepararse para el papel que está llamado a desempeñar según sus aptitudes, pues se parte de que todos «tenemos funciones diferentes que cumplir, y es necesario que nos pongamos en armonía con aquella que nos incumbe. No estamos todos hechos para meditar; son necesarios hombres de sensación y de acción. Inversamente, hacen falta otros que tengan como función pensar» (Durkheim, 2001:61). De ahí que la educación deba fungir como instancia de socialización: incorporar a jóvenes a la función social asignada. Basada en los preceptos descritos, se hace evidente que la pedagogía invasora es alienante, forja la personalidad del oprimido, moldea su conciencia, hasta el punto en que el mutismo y la pasividad se interiorizan a grado tal que el oprimido llega a ver en su opresor su modelo de hombre (Martín, 2002). El maestro es, en este modelo pedagógico, el actor fundamental. En cambio, hablar de integración social implica que el hombre tiene la capacidad no solamente 
de leer la realidad y adaptarse a ella, sino que la incorpora, la acomoda a sus esquemas y construye una visión propia que le permite actuar en ella para transformarla. Desde esta perspectiva, el hombre abandona el mutismo para denunciar los elementos de la realidad que no le favorecen y anunciar cambios colectivos en una situación de opresión (Freire, 1997).

En el proceso de integración social, el hombre se reconoce como sujeto, pues forma parte central de las decisiones de actuación en la vida cotidiana, es el actor principal de los hechos sociales. Esto es posible cuando los grupos sociales han accedido al proceso de concienciación, el cual, como ya se explicó a profundidad, inicia con una problematización del mundo concreto, mediante la palabra se genera el encuentro entre oprimidos que denuncian su situación para hacer posible la anunciación de una nueva realidad, es decir, construyen de manera colectiva, a través de la reflexión, formas de acción para transformarla.

La integración social implica seres de reflexión y acción que saben leer la realidad y construyen medios necesarios para modificarla. Su relación será dialógica por naturaleza y vivirán un proceso educativo permanente, donde aprenderán, a partir de la interacción con los otros y con el mundo, formas para actuar en el contexto cultural. Por ende, la noción de integración social es el ingrediente principal para demarcar una pedagogía liberadora, que se constituya en el eje que direcciona los cambios sociales hacia la justicia y la democracia. 


\section{Pedagogía crítica en la construcción de una escuela democrática}

Pensar un modelo pedagógico democrático al interior de las escuelas implica que éstas se configuren en agencias críticas (Giroux, 1998), formadoras para la integración social, donde se formen ciudadanos con herramientas suficientes para cuestionar de manera informada el orden establecido, las relaciones de poder que lo envisten, pero también que identifiquen y encaucen mecanismos de contestación y resistencia que se pueden gestar al interior del espacio escolar. Concebir a las escuelas como agencias críticas implica superar la idea de espacios técnicos, de capacitación y especialización para determinados papeles sociales. Visualiza al currículum como detonador de reflexión, como problematizador del aprendizaje donde todos los involucrados puedan construir su conocimiento en la interacción con los otros. Este conocimiento dependerá de los referentes teóricos y empíricos que posee cada sujeto y de las interacciones del currículum.

Además, la pedagogía crítica pone atención al currículum oculto, devela y enfrenta sus contradicciones, pues queda claro que

no es el saber ni el saber hacer la bisagra de la acción educativa; es el niño, el adolescente, que deben ser preparados para vivir con sus semejantes, para dialogar con ellos, para participar en sociedades gradualmente más complejas y más tiránicas, sin dejar por ello de ser ellos mismos, sin ser dominados, avasallados por máquinas y burocracias de cualquier tipo (Merani, 1969:67).

Así, los contenidos curriculares serán siempre detonadores de aprendizaje a partir de la problematización y enfrentamiento con la realidad 
de manera viable, flexible y sistemática. El nodo de la pedagogía crítica se encuentra en desentrañar el sentido político del acto educativo, buscando con ello la construcción de relaciones pedagógicas de diálogo entre agentes sociales y educativos para acercarse al conocimiento. Esta relación exige que el profesor rompa con la función de invasor cultural, para convertirse en un sujeto reflexivo y militante de la acción crítica; lo cual implica hacer consciente las relaciones de poder que se establecen en torno del saber. Es necesario que el educador sea capaz de leer los intereses que los estudiantes tratan de objetivar y que haga explícita la confrontación con sus propios intereses. Esto permite identificar conductas de oposición que los estudiantes de manera cotidiana generan al interior del aula, cuando sienten la coerción de los dispositivos de poder que de manera consciente o inconsciente ejercen profesores. La oposición en tanto contestación espontánea, no contienen la fuerza política suficiente para contrarrestar la dominación; sin embargo, la oposición está enraizada en una reacción a la autoridad (Giroux, 2003).

Por tanto, no basta con que los profesores críticos identifiquen los actos de oposición, tendrán que problematizar a los estudiantes para que aprendan a encauzar la contestación hacia actos de resistencia, es decir, en actos de enfrentamiento con el ejercicio omnímodo del poder, que lo desafíen políticamente, de forma colectiva y organizada. Una pedagogía que desafía al poder exige que todos los actores involucrados en el acto educativo dialoguen constantemente sobre sus intereses pedagógicos, sus experiencias y necesidades de aprendizaje. También requiere de la reflexión incesante de las posibilidades, medios, esfuerzos y recursos que cada uno puede aportar a la construcción de saberes colectivos. En esta tarea, el profesor deberá fungir como problematizador y acercar a los estudiantes al conocimiento. En 
su labor cotidiana, el profesor crítico tiene el reto de saber leer sus aprendizajes previos para no invadirlos culturalmente, tiene que problematizarlos y construir estrategias que permitan a los involucrados interactuar con el objeto de conocimiento a través de aproximaciones sucesivas, distintas, aprehenderlo y construirlo de forma individual, rescatando saberes colectivos. En ese sentido, maestro y alumno viven una relación horizontal, complementándose, problematizándose y potencializando aprendizajes. El aula se convierte en espacio de interacción, donde el currículo se construye activamente y es sólo un pretexto para detonar conflictos cognitivos que generen la construcción de conocimientos (Not, 1983).

A diferencia de la pedagogía invasora, cuyo objetivo central es la imposición de un currículo técnico, que prepara a estudiantes y maestros para desarrollar una función social que sirve a intereses ajenos a los suyos, la pedagogía crítica devela el currículum oculto de la escuela y establece una relación significativa con los contenidos, pues éstos se enmarcan en las vivencias y necesidades del grupo, se aprenden respetando ritmos y estilos de aprendizaje, grupales e individuales. El trabajo colectivo es el que nutre el proceso de aprendizaje y con ello se gesta una situación gnoseológica acerca de un objeto común que es percibido desde diversas miradas culturales y expresada en diferentes lenguas, todas ellas en igualdad de importancia y sin que ninguna de ellas implante su hegemonía sobre otras. Otro ámbito importante que debemos considerar en este esbozo de una pedagogía crítica es de orden psicológico, del cual rescataremos principalmente las aportaciones de Vygotsky con referencia al desarrollo de las funciones psicológicas superiores (Wertsch, 1988). Al respecto, sostiene que de forma individual todos tenemos un desarrollo real de nuestro pensamiento, y que de acuerdo con el medio social donde nos desenvolvemos 
y con los objetos de conocimiento con que interactuamos, tenemos un desarrollo potencial, al cual podemos acceder al trabajar con otros. Vygotsky lo denomina zona de desarrollo próximo y la explica como un espacio de interacción en el que se comparten las construcciones de cada uno y con ayuda de los demás; cada individuo desarrolla sus funciones psicológicas a un nivel superior del real, que está compartiendo en ese momento, y con ello acercarse al desarrollo potencial que le ofrece el contexto.

Para generar ambientes de aprendizaje de este tipo, al profesor crítico no le bastará una intencionalidad política democrática, tendrá además que contar con amplio conocimiento de procesos psicológicos y pedagógicos que permitan problematizar el aprendizaje de los involucrados en el acto educativo, por lo que su tarea de concienciación es informada, profunda y permanente. La figura del profesor como pedagogo crítico se aleja de los cánones del profesor activista de la escuela nueva, el cual utilizaba la actividad como forma de manipulación para invadir culturalmente. De ahí que para formar hombres de praxis, profesores y estudiantes, se tendrá que enfrentar un proceso educativo de problematización, de reflexión y de acción continua, dialogando explícitamente sus intereses y necesidades con el grupo.

\section{Conclusiones}

La realidad educativa nos emplaza a resignificar las nociones de la pedagogía crítica que permitan sentar bases para la construcción de un modelo dialógico que atienda las necesidades de aprendizaje, contextuales y culturales de los grupos marginados de la educación oficialista que se oferta 
en México. Esta tarea se presenta como urgente debido a la segregación de las poblaciones menos favorecidas con respecto al acceso y permanencia en el sistema educativo que han generado las reformas educativas actuales. Esto debido al modelo pedagógico que fomentan e imponen y sus repercusiones sociales.

Centrar el desarrollo de la educación en torno de una evaluación verificadora, memorística, descontextualizada y en última instancia punitiva, ha llevado a los educadores a involucrarse en un modelo pedagógico que reduce su importante labor a la de un técnico desarrollador de programas, transmisor de conocimientos vacuos, ajenos a la vida, necesidades e intereses y cultura de estudiantes. Se fomenta la figura del docente como administrador que cumple procesos exigidos por la burocracia institucional y tendrá que mostrar evidencia de que realiza cada acción que le exige el proceso evaluativo con los indicadores que se le precisan. Esto lo cosifica como un ente activo que puede generar espacios democráticos donde se formen ciudadanos críticos capaces de leer el mundo y transformarlo.

Concebir la educación de calidad como aquella que es certificada a partir de exámenes estandarizados no solamente cosifica al profesor e impide la gestación de procesos sociales democráticos y emancipatorios, sino que además fomenta la marginación de los desposeídos, pues al poner a la evaluación estandarizada como instrumento central para alcanzarse, se prefigura una homogenización cultural y social a la cual todos los individuos deben responder, sin tomar en cuenta que son precisamente las diferencias las que debieran marcar el rumbo en la construcción de modelos educativos. La homogenización parte de que existe igualdad en el acceso a los bienes materiales y culturales, por lo que alcanzar el estándar exige contar con una serie de elementos de esta índole, y que al carecer de ellos, 
como es el caso de quienes viven en marginación y pobreza, la evaluación ejecuta su función de selección social (Parsons, 1985) y asigna papeles que se encuentran fuera del sistema educativo.

Esta situación concreta nos obliga a reconocer la premisa de la pedagogía crítica de que todo acto educativo ineludiblemente es un acto político donde se confrontan los intereses de una clase social o cultura hegemónica y los intereses de quienes son oprimidos por ella. De manera que se recupera también el proceso pedagógico a través del cual se fomenta esta opresión, y que en el artículo se caracteriza como pedagogía bancaria. Se demuestra cómo dicho modelo que prevalece en nuestra realidad no solamente tiene implicaciones en lo cognitivo al transmitir saberes inmutables, vacíos de significado, sino que fomenta la disciplinarización del cuerpo y la mente para alcanzar estándares impuestos desde fuera, que les impiden a educadores y educandos decir su palabra, leer su realidad, condenándoles al mutismo, al ajustamiento y a la incorporación social. De ahí que de igual modo se asumiera en este escrito la obligación de enunciar los elementos de la pedagogía crítica que dan cuenta de procesos de concienciación y de transformación de la realidad. Por tanto, se recupera la importancia de que los educadores y grupos oprimidos rescaten el valor de su palabra mediante el diálogo, eso será lo que les permita pensar su mundo y actuar en él de forma colectiva y organizada. Reconociendo que romper con procesos de invasión cultural y establecer relaciones pedagógicas sustentadas en el diálogo no son tareas sencillas, se intentó además evidenciar los componentes del proceso de comunicación, como una posibilidad para leer el mundo, comprenderlo y organizar su transformación. Ello implicó desentrañar los procesos de ajustamiento, incorporación e integración social que se generan con el acto educativo intencionado. 
Con la finalidad de que no se interprete el esbozo que aquí se presenta como una propuesta idealista, sujeta a voluntad de los educadores, se profundizó en las nociones antagónicas de alienación y de concienciación. Particularmente se hizo hincapié en cómo se gesta el proceso de concienciación a través de la problematización de la realidad en los sujetos, sin cuya participación, a pesar de los determinantes históricos, no es posible resistir a la dominación. Se recupera la constitución como seres de reflexión y de acción como condición sine qua non para la construcción de una realidad mejor. En síntesis, baste decir que el presente escrito simboliza el inicio de una serie de esfuerzos colectivos para resignificar la pedagogía crítica como herramienta teórico-práctica en un afán de delinear un modelo pedagógico fincado en la comunicación y construcción colectiva de conocimientos. De manera que, si coadyuva a cuestionar el estado actual de la educación a partir de los argumentos vertidos, podremos seguir caminando en el rumbo correcto.

\section{Referencias}

Bourdieu, Pierre (2000), Capital cultural, escuela y espacio social, México, Siglo XXI.

Durkheim, Émile (2001), Educación y sociología, México, Coyoacán.

Freire, Paulo (1990), Pedagogía del oprimido, México, Siglo XXI. (1997), ¿Extensión o comunicación?, México, Siglo XXI. (1997), La educación como práctica de la libertad, México, Siglo XXI. (2001), La importancia de leer el proceso de liberación, México, Siglo XXI.

Giroux, Henry (1998), La escuela y la lucha por la ciudadanía, México, Siglo XXI. 
(1997), La educación como práctica de la libertad, México, Siglo XXI. (2003), Teoría y resistencia en educación, México, Siglo XXI.

Kaplún, Mario (2002), Una pedagogía de la comunicación, Cuba, Caminos.

Martín-Barbero, Jesús (2002), La educación desde la comunicación, Colombia, Norma.

Marx, Karl y Friederich Engels (1974), La ideología alemana, México, Ediciones de Cultura Popular.

(1982), Obras fundamentales (tomo I), México, Fondo de Cultura Económica.

(1997), La educación como práctica de la libertad, México, Siglo XXI.

Merani, Alberto L. (1969), Psicología y pedagogía, México, Grijalbo.

Not, Louis (1983), Las pedagogías del conocimiento, México, Fondo de Cultura Económica.

Parsons, Talcott (1985), «La educación como asignadora de roles y factor de selección social», en María de Ibarrola, Las dimensiones sociales de la educación, México, Ediciones Caballitos.

Poulantzas, Nicos (1985), Poder político y clases sociales en el Estado capitalista, México, Siglo XXI.

Wertsch, James (1988), Vygotsky y la formación social de la mente, España, Paidós. 